\title{
Qualitative Research: Data Collection, Analysis, and Management
}

\author{
Jane Sutton and Zubin Austin
}

\section{INTRODUCTION}

Tn an earlier paper, ${ }^{1}$ we presented an introduction to using qualitative research methods in pharmacy practice. In this article, we review some principles of the collection, analysis, and management of qualitative data to help pharmacists interested in doing research in their practice to continue their learning in this area. Qualitative research can help researchers to access the thoughts and feelings of research participants, which can enable development of an understanding of the meaning that people ascribe to their experiences. Whereas quantitative research methods can be used to determine how many people undertake particular behaviours, qualitative methods can help researchers to understand how and why such behaviours take place. Within the context of pharmacy practice research, qualitative approaches have been used to examine a diverse array of topics, including the perceptions of key stakeholders regarding prescribing by pharmacists and the postgraduation employment experiences of young pharmacists (see "Further Reading" section at the end of this article).

In the previous paper, ${ }^{1}$ we outlined 3 commonly used methodologies: ethnography ${ }^{2}$, grounded theory ${ }^{3}$, and phenomenology. ${ }^{4}$ Briefly, ethnography involves researchers using direct observation to study participants in their "real life" environment, sometimes over extended periods. Grounded theory and its later modified versions (e.g., Strauss and Corbin ${ }^{5}$ ) use face-to-face interviews and interactions such as focus groups to explore a particular research phenomenon and may help in clarifying a less-well-understood problem, situation, or context. Phenomenology shares some features with grounded theory (such as an exploration of participants' behaviour) and uses similar techniques to collect data, but it focuses on understanding how human beings experience their world. It gives researchers the opportunity to put themselves in another person's shoes and to understand the subjective experiences of participants. ${ }^{6}$ Some researchers use qualitative methodologies but adopt a different standpoint, and an example of this appears in the work of Thurston and others, ${ }^{7}$ discussed later in this paper.

Qualitative work requires reflection on the part of researchers, both before and during the research process, as a way of providing context and understanding for readers. When being reflexive, researchers should not try to simply ignore or avoid their own biases (as this would likely be impossible); instead, reflexivity requires researchers to reflect upon and clearly articulate their position and subjectivities (world view, perspectives, biases), so that readers can better understand the filters through which questions were asked, data were gathered and analyzed, and findings were reported. From this perspective, bias and subjectivity are not inherently negative but they are unavoidable; as a result, it is best that they be articulated up-front in a manner that is clear and coherent for readers.

\section{THE PARTICIPANT'S VIEWPOINT}

What qualitative study seeks to convey is why people have thoughts and feelings that might affect the way they behave. Such study may occur in any number of contexts, but here, we focus on pharmacy practice and the way people behave with regard to medicines use (e.g., to understand patients' reasons for nonadherence with medication therapy or to explore physicians' resistance to pharmacists' clinical suggestions). As we suggested in our earlier article, ${ }^{1}$ an important point about qualitative research is that there is no attempt to generalize the findings to a wider population. Qualitative research is used to gain insights into people's feelings and thoughts, which may provide the basis for a future stand-alone qualitative study or may help researchers to map out survey instruments for use in a quantitative study. It is also possible to use different types of research in the same study, an approach known as "mixed methods" research, and further reading on this topic may be found at the end of this paper.

The role of the researcher in qualitative research is to attempt to access the thoughts and feelings of study participants. 
This is not an easy task, as it involves asking people to talk about things that may be very personal to them. Sometimes the experiences being explored are fresh in the participant's mind, whereas on other occasions reliving past experiences may be difficult. However the data are being collected, a primary responsibility of the researcher is to safeguard participants and their data. Mechanisms for such safeguarding must be clearly articulated to participants and must be approved by a relevant research ethics review board before the research begins. Researchers and practitioners new to qualitative research should seek advice from an experienced qualitative researcher before embarking on their project.

\section{DATA COLLECTION}

Whatever philosophical standpoint the researcher is taking and whatever the data collection method (e.g., focus group, one-to-one interviews), the process will involve the generation of large amounts of data. In addition to the variety of study methodologies available, there are also different ways of making a record of what is said and done during an interview or focus group, such as taking handwritten notes or video-recording. If the researcher is audio- or video-recording data collection, then the recordings must be transcribed verbatim before data analysis can begin. As a rough guide, it can take an experienced researcher/transcriber 8 hours to transcribe one 45-minute audio-recorded interview, a process than will generate 20-30 pages of written dialogue.

Many researchers will also maintain a folder of "field notes" to complement audio-taped interviews. Field notes allow the researcher to maintain and comment upon impressions, environmental contexts, behaviours, and nonverbal cues that may not be adequately captured through the audio-recording; they are typically handwritten in a small notebook at the same time the interview takes place. Field notes can provide important context to the interpretation of audio-taped data and can help remind the researcher of situational factors that may be important during data analysis. Such notes need not be formal, but they should be maintained and secured in a similar manner to audio tapes and transcripts, as they contain sensitive information and are relevant to the research. For more information about collecting qualitative data, please see the "Further Reading" section at the end of this paper.

\section{DATA ANALYSIS AND MANAGEMENT}

If, as suggested earlier, doing qualitative research is about putting oneself in another person's shoes and seeing the world from that person's perspective, the most important part of data analysis and management is to be true to the participants. It is their voices that the researcher is trying to hear, so that they can be interpreted and reported on for others to read and learn from. To illustrate this point, consider the anonymized transcript excerpt presented in Appendix 1, which is taken from a research interview conducted by one of the authors (J.S.). We refer to this excerpt throughout the remainder of this paper to illustrate how data can be managed, analyzed, and presented.

\section{Interpretation of Data}

Interpretation of the data will depend on the theoretical standpoint taken by researchers. For example, the title of the research report by Thurston and others, " ${ }^{7}$ "Discordant indigenous and provider frames explain challenges in improving access to arthritis care: a qualitative study using constructivist grounded theory," indicates at least 2 theoretical standpoints. The first is the culture of the indigenous population of Canada and the place of this population in society, and the second is the social constructivist theory used in the constructivist grounded theory method. With regard to the first standpoint, it can be surmised that, to have decided to conduct the research, the researchers must have felt that there was anecdotal evidence of differences in access to arthritis care for patients from indigenous and nonindigenous backgrounds. With regard to the second standpoint, it can be surmised that the researchers used social constructivist theory because it assumes that behaviour is socially constructed; in other words, people do things because of the expectations of those in their personal world or in the wider society in which they live. (Please see the "Further Reading" section for resources providing more information about social constructivist theory and reflexivity.) Thus, these 2 standpoints (and there may have been others relevant to the research of Thurston and others ${ }^{7}$ ) will have affected the way in which these researchers interpreted the experiences of the indigenous population participants and those providing their care. Another standpoint is feminist standpoint theory which, among other things, focuses on marginalized groups in society. Such theories are helpful to researchers, as they enable us to think about things from a different perspective. Being aware of the standpoints you are taking in your own research is one of the foundations of qualitative work. Without such awareness, it is easy to slip into interpreting other people's narratives from your own viewpoint, rather than that of the participants.

To analyze the example in Appendix 1, we will adopt a phenomenological approach because we want to understand how the participant experienced the illness and we want to try to see the experience from that person's perspective. It is important for the researcher to reflect upon and articulate his or her starting point for such analysis; for example, in the example, the coder could reflect upon her own experience as a female of a majority ethnocultural group who has lived within middle class and upper middle class settings. This personal history therefore forms the filter through which the data will be examined. This filter does not diminish the quality or significance of the analysis, since every researcher has his or her own filters; however, by explicitly stating and acknowledging what these filters are, the researcher makes it easer for readers to contextualize the work. 


\section{Transcribing and Checking}

For the purposes of this paper it is assumed that interviews or focus groups have been audio-recorded. As mentioned above, transcribing is an arduous process, even for the most experienced transcribers, but it must be done to convert the spoken word to the written word to facilitate analysis. For anyone new to conducting qualitative research, it is beneficial to transcribe at least one interview and one focus group. It is only by doing this that researchers realize how difficult the task is, and this realization affects their expectations when asking others to transcribe. If the research project has sufficient funding, then a professional transcriber can be hired to do the work. If this is the case, then it is a good idea to sit down with the transcriber, if possible, and talk through the research and what the participants were talking about. This background knowledge for the transcriber is especially important in research in which people are using jargon or medical terms (as in pharmacy practice). Involving your transcriber in this way makes the work both easier and more rewarding, as he or she will feel part of the team. Transcription editing software is also available, but it is expensive. For example, ELAN (more formally known as EUDICO Linguistic Annotator, developed at the Technical University of Berlin) ${ }^{8}$ is a tool that can help keep data organized by linking media and data files (particularly valuable if, for example, video-taping of interviews is complemented by transcriptions). It can also be helpful in searching complex data sets. Products such as ELAN do not actually automatically transcribe interviews or complete analyses, and they do require some time and effort to learn; nonetheless, for some research applications, it may be a valuable to consider such software tools.

All audio recordings should be transcribed verbatim, regardless of how intelligible the transcript may be when it is read back. Lines of text should be numbered. Once the transcription is complete, the researcher should read it while listening to the recording and do the following: correct any spelling or other errors; anonymize the transcript so that the participant cannot be identified from anything that is said (e.g., names, places, significant events); insert notations for pauses, laughter, looks of discomfort; insert any punctuation, such as commas and full stops (periods) (see Appendix 1 for examples of inserted punctuation), and include any other contextual information that might have affected the participant (e.g., temperature or comfort of the room).

Dealing with the transcription of a focus group is slightly more difficult, as multiple voices are involved. One way of transcribing such data is to "tag" each voice (e.g., Voice A, Voice B). In addition, the focus group will usually have 2 facilitators, whose respective roles will help in making sense of the data. While one facilitator guides participants through the topic, the other can make notes about context and group dynamics. More information about group dynamics and focus groups can be found in resources listed in the "Further Reading" section.

\section{Reading between the Lines}

During the process outlined above, the researcher can begin to get a feel for the participant's experience of the phenomenon in question and can start to think about things that could be pursued in subsequent interviews or focus groups (if appropriate). In this way, one participant's narrative informs the next, and the researcher can continue to interview until nothing new is being heard or, as it says in the text books, "saturation is reached". While continuing with the processes of coding and theming (described in the next 2 sections), it is important to consider not just what the person is saying but also what they are not saying. For example, is a lengthy pause an indication that the participant is finding the subject difficult, or is the person simply deciding what to say? The aim of the whole process from data collection to presentation is to tell the participants' stories using exemplars from their own narratives, thus grounding the research findings in the participants' lived experiences.

Smith ${ }^{9}$ suggested a qualitative research method known as interpretative phenomenological analysis, which has 2 basic tenets: first, that it is rooted in phenomenology, attempting to understand the meaning that individuals ascribe to their lived experiences, and second, that the researcher must attempt to interpret this meaning in the context of the research. That the researcher has some knowledge and expertise in the subject of the research means that he or she can have considerable scope in interpreting the participant's experiences. Larkin and others ${ }^{10}$ discussed the importance of not just providing a description of what participants say. Rather, interpretative phenomenological analysis is about getting underneath what a person is saying to try to truly understand the world from his or her perspective.

\section{Coding}

Once all of the research interviews have been transcribed and checked, it is time to begin coding. Field notes compiled during an interview can be a useful complementary source of information to facilitate this process, as the gap in time between an interview, transcribing, and coding can result in memory bias regarding nonverbal or environmental context issues that may affect interpretation of data.

Coding refers to the identification of topics, issues, similarities, and differences that are revealed through the participants' narratives and interpreted by the researcher. This process enables the researcher to begin to understand the world from each participant's perspective. Coding can be done by hand on a hard copy of the transcript, by making notes in the margin or by highlighting and naming sections of text. More commonly, researchers use qualitative research software (e.g., NVivo, QSR International Pty Ltd; www.qsrinternational.com/products nvivo.aspx) to help manage their transcriptions. It is advised that researchers undertake a formal course in the use of such software or seek supervision from a researcher experienced in these tools. 
Returning to Appendix 1 and reading from lines 8-11, a code for this section might be "diagnosis of mental health condition", but this would just be a description of what the participant is talking about at that point. If we read a little more deeply, we can ask ourselves how the participant might have come to feel that the doctor assumed he or she was aware of the diagnosis or indeed that they had only just been told the diagnosis. There are a number of pauses in the narrative that might suggest the participant is finding it difficult to recall that experience. Later in the text, the participant says "nobody asked me any questions about my life" (line 19). This could be coded simply as "health care professionals' consultation skills", but that would not reflect how the participant must have felt never to be asked anything about his or her personal life, about the participant as a human being. At the end of this excerpt, the participant just trails off, recalling that no-one showed any interest, which makes for very moving reading. For practitioners in pharmacy, it might also be pertinent to explore the participant's experience of akathisia and why this was left untreated for 20 years.

One of the questions that arises about qualitative research relates to the reliability of the interpretation and representation of the participants' narratives. There are no statistical tests that can be used to check reliability and validity as there are in quantitative research. However, work by Lincoln and Guba ${ }^{11}$ suggests that there are other ways to "establish confidence in the 'truth' of the findings" (p. 218). They call this confidence "trustworthiness" and suggest that there are 4 criteria of trustworthiness: credibility (confidence in the "truth" of the findings), transferability (showing that the findings have applicability in other contexts), dependability (showing that the findings are consistent and could be repeated), and confirmability (the extent to which the findings of a study are shaped by the respondents and not researcher bias, motivation, or interest).

One way of establishing the "credibility" of the coding is to ask another researcher to code the same transcript and then to discuss any similarities and differences in the 2 resulting sets of codes. This simple act can result in revisions to the codes and can help to clarify and confirm the research findings.

\section{Theming}

Theming refers to the drawing together of codes from one or more transcripts to present the findings of qualitative research in a coherent and meaningful way. For example, there may be examples across participants' narratives of the way in which they were treated in hospital, such as "not being listened to" or "lack of interest in personal experiences" (see Appendix 1). These may be drawn together as a theme running through the narratives that could be named "the patient's experience of hospital care". The importance of going through this process is that at its conclusion, it will be possible to present the data from the interviews using quotations from the individual transcripts to illustrate the source of the researchers' interpretations. Thus, when the findings are organized for presentation, each theme can become the heading of a section in the report or presentation. Underneath each theme will be the codes, examples from the transcripts, and the researcher's own interpretation of what the themes mean. Implications for real life (e.g., the treatment of people with chronic mental health problems) should also be given.

\section{DATA SYNTHESIS}

In this final section of this paper, we describe some ways of drawing together or "synthesizing" research findings to represent, as faithfully as possible, the meaning that participants ascribe to their life experiences. This synthesis is the aim of the final stage of qualitative research. For most readers, the synthesis of data presented by the researcher is of crucial significance-this is usually where "the story" of the participants can be distilled, summarized, and told in a manner that is both respectful to those participants and meaningful to readers. There are a number of ways in which researchers can synthesize and present their findings, but any conclusions drawn by the researchers must be supported by direct quotations from the participants. In this way, it is made clear to the reader that the themes under discussion have emerged from the participants' interviews and not the mind of the researcher. The work of Latif and others ${ }^{12}$ gives an example of how qualitative research findings might be presented.

\section{Planning and Writing the Report}

As has been suggested above, if researchers code and theme their material appropriately, they will naturally find the headings for sections of their report. Qualitative researchers tend to report "findings" rather than "results", as the latter term typically implies that the data have come from a quantitative source. The final presentation of the research will usually be in the form of a report or a paper and so should follow accepted academic guidelines. In particular, the article should begin with an introduction, including a literature review and rationale for the research. There should be a section on the chosen methodology and a brief discussion about why qualitative methodology was most appropriate for the study question and why one particular methodology (e.g., interpretative phenomenological analysis rather than grounded theory) was selected to guide the research. The method itself should then be described, including ethics approval, choice of participants, mode of recruitment, and method of data collection (e.g., semistructured interviews or focus groups), followed by the research findings, which will be the main body of the report or paper. The findings should be written as if a story is being told; as such, it is not necessary to have a lengthy discussion section at the end. This is because much of the discussion will take place around the participants' quotes, such that all that is needed to close the report or paper is a summary, limitations of the research, and the implications that the research has for 
practice. As stated earlier, it is not the intention of qualitative research to allow the findings to be generalized, and therefore this is not, in itself, a limitation.

Planning out the way that findings are to be presented is helpful. It is useful to insert the headings of the sections (the themes) and then make a note of the codes that exemplify the thoughts and feelings of your participants. It is generally advisable to put in the quotations that you want to use for each theme, using each quotation only once. After all this is done, the telling of the story can begin as you give your voice to the experiences of the participants, writing around their quotations. Do not be afraid to draw assumptions from the participants' narratives, as this is necessary to give an in-depth account of the phenomena in question. Discuss these assumptions, drawing on your participants' words to support you as you move from one code to another and from one theme to the next. Finally, as appropriate, it is possible to include examples from literature or policy documents that add support for your findings. As an exercise, you may wish to code and theme the sample excerpt in Appendix 1 and tell the participant's story in your own way. Further reading about "doing" qualitative research can be found at the end of this paper.

\section{CONCLUSIONS}

Qualitative research can help researchers to access the thoughts and feelings of research participants, which can enable development of an understanding of the meaning that people ascribe to their experiences. It can be used in pharmacy practice research to explore how patients feel about their health and their treatment. Qualitative research has been used by pharmacists to explore a variety of questions and problems (see the "Further Reading" section for examples). An understanding of these issues can help pharmacists and other health care professionals to tailor health care to match the individual needs of patients and to develop a concordant relationship. Doing qualitative research is not easy and may require a complete rethink of how research is conducted, particularly for researchers who are more familiar with quantitative approaches. There are many ways of conducting qualitative research, and this paper has covered some of the practical issues regarding data collection, analysis, and management. Further reading around the subject will be essential to truly understand this method of accessing peoples' thoughts and feelings to enable researchers to tell participants' stories.

\section{References}

1. Austin ZA, Sutton J. Qualitative research: getting started. Can J Hosp Pharm. 2014;67(6):436-40.

2. Hammersley M, Atkinson P. Ethnography: principles in practice. London (UK): Taylor and Francis; 2007.

3. What is grounded theory? Mill Valley (CA): Grounded Theory Institute; 2008 [cited 2015 May 2]. Available from: www.groundedtheory.com/whatis-gt.aspx

4 Brewer J. Naturalism. In: Miller RL, Brewer JD, editors. The A-Z of social research. London (UK): Sage Publications; 2003. p. 147-59.
5. Strauss AL, Corbin J. Basics of qualitative research: grounded theory procedures and techniques. Thousand Oaks (CA): Sage Publications; 1998.

6. Smith JA, Jarman M, Osborn M. Doing interpretative phenomenological analysis. In: Murray M, Chamberlain K, editors. Qualitative health psychology: theories and methods. London (UK): Sage Publications; 1999. p. 218-40.

7. Thurston WE, Coupal S, Jones CA, Crowshoe LF, Marshall DA, Homik J, et al. Discordant indigenous and provider frames explain challenges in improving access to arthritis care: a qualitative study using constructivist grounded theory. Int J Equity Health. 2014;13:46.

8. Rosenfelder R. A short introduction to transcribing with ELAN. Philadelphia (PA): University of Pennsylvania, Linguistics Lab; 2011 [cited 2015 Jun 4]. Available from: http://fave.ling.upenn.edu/downloads/ELAN_ Introduction.pdf Title

9. Smith JA. Beyond the divide between cognition and discourse: using interpretative phenomenological analysis in health psychology. Psychol Health. 1996;11(2):261-71.

10. Larkin M, Watts S, Clifton E. Giving voice and making sense in interpretative phenomenological analysis. Qual Res Psychol. 2006;3(2):102-20.

11. Lincoln YS, Guba EG. Naturalistic inquiry. Thousand Oaks (CA): Sage Publications; 1985.

12. Latif A, Boardman HF, Pollock K. A qualitative study exploring the impact and consequence of the medicines use review service on pharmacy supportstaff. Pharm Pract. 2013;11(2):118-24.

\section{Further Reading}

Examples of Qualitative Research in Pharmacy Practice

Farrell B, Pottie K, Woodend K, Yao V, Dolovich L, Kennie N, et al. Shifts in expectations: evaluating physicians' perceptions as pharmacists integrated into family practice. J Interprof Care. 2010;24(1):80-9.

Gregory P, Austin Z. Postgraduation employment experiences of new pharmacists in Ontario in 2012-2013. Can Pharm J. 2014;147(5):290-9.

Marks PZ, Jennnings B, Farrell B, Kennie-Kaulbach N, Jorgenson D, PearsonSharpe J, et al. "I gained a skill and a change in attitude": a case study describing how an online continuing professional education course for pharmacists supported achievement of its transfer to practice outcomes. Can J Univ Contin Educ. 2014;40(2):1-18.

Nair KM, Dolovich L, Brazil K, Raina P. It's all about relationships: a qualitative study of health researchers' perspectives on interdisciplinary research. BMC Health Serv Res. 2008;8:110.

Pojskic N, MacKeigan L, Boon H, Austin Z. Initial perceptions of key stakeholders in Ontario regarding independent prescriptive authority for pharmacists. Res Soc Adm Pharm. 2014;10(2):341-54.

Qualitative Research in General

Breakwell GM, Hammond S, Fife-Schaw C, editors. Research methods in psychology. Thousand Oaks (CA): Sage Publications; 1995.

Given LM. 100 questions (and answers) about qualitative research. Thousand Oaks (CA): Sage Publications; 2015.

Miles B, Huberman AM. Qualitative data analysis. Thousand Oaks (CA): Sage Publications; 2009.

Patton M. Qualitative research and evaluation methods. Thousand Oaks (CA): Sage Publications; 2002.

Willig C. Introducing qualitative research in psychology. Buckingham (UK): Open University Press; 2001.

Group Dynamics in Focus Groups

Farnsworth J, Boon B. Analysing group dynamics within the focus group. Qual Res. 2010;10(5):605-24.

\section{Social Constructivism}

Social constructivism. Berkeley (CA): University of California, Berkeley, Berkeley Graduate Division, Graduate Student Instruction Teaching \& Resource Center; [cited 2015 June 4]. Available from: http://gsi.berkeley.edu/gsi-guidecontents/learning-theory-research/social-constructivism/

\section{Mixed Methods}

Creswell J. Research design: qualitative, quantitative, and mixed methods approaches. Thousand Oaks (CA): Sage Publications; 2009 
This single copy is for your personal, non-commercial use only.

For permission to reprint multiple copies or to order presentation-ready copies for distribution, contact CJHP at cjhpedit@cshp.ca

Collecting Qualitative Data

Arksey H, Knight P. Interviewing for social scientists: an introductory resource with examples. Thousand Oaks (CA): Sage Publications; 1999.

Guest G, Namey EE, Mitchel ML. Collecting qualitative data: a field manual for applied research. Thousand Oaks (CA): Sage Publications; 2013.

Constructivist Grounded Theory

Charmaz, K. Grounded theory: objectivist and constructivist methods. In: Denzin N, Lincoln Y, editors. Handbook of qualitative research. 2nd ed. Thousand Oaks (CA): Sage Publications; 2000. p. 509-35.
Zubin Austin, BScPhm, MBA, MISc, PhD, is a Professor in the Leslie Dan Faculty of Pharmacy and Murray B Koffler Chair in Management, University of Toronto, Toronto, Ontario.

Jane Sutton, BSc(Hons), PhD, CPsychol, AFBPsS, is a Visiting Research Fellow with the Department of Pharmacy and Pharmacology, University of Bath, Bath, United Kingdom.

Competing interests: None declared.

Address correspondence to:

Dr Zubin Austin

Leslie Dan Faculty of Pharmacy

University of Toronto

144 College Street

Toronto ON M5S 3M2

e-mail: zubin.austin@utoronto.ca

\section{Appendix 1. Excerpt from a sample transcript}

The participant (age late 50s) had suffered from a chronic mental health illness for 30 years. The participant had become a "revolving door patient," someone who is frequently in and out of hospital. As the participant talked about past experiences, the researcher asked:

\section{What was treatment like 30 years ago?}

2 Umm - well it was pretty much they could do what they wanted with you because I was put into the er, the er kind of system er, I was just on

3 endless section threes.

4 Really...

5 But what I didn't realize until later was that if you haven't actually posed a threat to someone or yourself they can't really do that but I didn't know

6 that. So wh-when I first went into hospital they put me on the forensic ward 'cause they said, "We don't think you'll stay here we think you'll just

7 run-run away." So they put me then onto the acute admissions ward and - er - I can remember one of the first things I recall when I got onto that

8 ward was sitting down with a er a Dr XXX. He had a book this thick [gestures] and on each page it was like three questions and he went through

9 all these questions and I answered all these questions. So we're there for I don't maybe two hours doing all that and he asked me he said "well

10 when did somebody tell you then that you have schizophrenia" I said "well nobody's told me that" so he seemed very surprised but nobody had

11 actually [pause] whe-when I first went up there under police escort erm the senior kind of consultants people I'd been to where I was staying and

12 ermm so er [pause] I . . . the, I can remember the very first night that I was there and given this injection in this muscle here [gestures] and just

13 having dreadful side effects the next day I woke up [pause]

14 Oh.

15 ... and I suffered that akathesia I swear to you, every minute of every day for about 20 years.

\section{Oh how awful.}

17 And that side of it just makes life impossible so the care on the wards [pause] umm I don't know it's kind of, it's kind of hard to put into words

18 [pause]. Because I'm not saying they were sort of like not friendly or interested but then nobody ever seemed to want to talk about your life [pause] 19 nobody asked me any questions about my life. The only questions that came into was they asked me if I'd be a volunteer for these student exams 20 and things and I said "yeah" so all the questions were like "oh what jobs have you done," er about your relationships and things and er but 21 nobody actually sat down and had a talk and showed some interest in you as a person you were just there basically [pause] um labelled and you 22 know there was there was [pause] but umm [pause] yeah . . .

This article is the 10th in the CJHP Research Primer Series, an initiative of the CJHP Editorial Board and the CSHP Research Committee. The planned 2-year series is intended to appeal to relatively inexperienced researchers, with the goal of building research capacity among practising pharmacists. The articles, presenting simple but rigorous guidance to encourage and support novice researchers, are being solicited from authors with appropriate expertise.

Previous articles in this series:

Bond CM. The research jigsaw: how to get started. Can J Hosp Pharm. 2014;67(1):28-30.

Tully MP. Research: articulating questions, generating hypotheses, and choosing study designs. Can J Hosp Pharm. 2014;67(1):31-4
Loewen P. Ethical issues in pharmacy practice research: an introductory guide. Can J Hosp Pharm. 2014;67(2):133-7.

Tsuyuki RT. Designing pharmacy practice research trials. Can J Hosp Pharm. 2014;67(3):226-9.

Bresee LC. An introduction to developing surveys for pharmacy practice research. Can J Hosp Pharm. 2014;67(4):286-91.

Gamble JM. An introduction to the fundamentals of cohort and case-control studies. Can J Hosp Pharm. 2014;67(5):366-72.

Austin Z, Sutton J. Qualitative research: getting started. Can J Hosp Pharm. 2014;67(6):436-40.

Houle $S$. An introduction to the fundamentals of randomized controlled trials in pharmacy research. Can J Hosp Pharm. 2014; 68(1):28-32.

Charrois TL. Systematic reviews: What do you need to know to get started? Can J Hosp Pharm. 2014;68(2):144-8. 